\title{
Loranthus Micranthus Extracts Suppress the Expression and Enzymatic Activity of Indoleamine 2, 3-Dioxygenase in Human Breast Cancer Cells via the Inhibition of JAK/STAT and NF-KB Pathways
}

\section{Azubuike P. Ebokaiwe}

Alex Ekwueme Federal University Ndufu-Alike

\section{Ting Peng}

Chengdu Institute of Biology

\section{Emmanuel M. Njoya}

Chengdu Institute of Biology

\section{Zongyuan Zhou}

Chengdu Institute of Biology

Ahmed A. Hussein

Cape Peninsula University of Technology

Guolin Zhang

Chengdu Institute of Biology

Fei Wang ( $\square$ wangfei@cib.ac.cn )

Chengdu Institute of Biology https://orcid.org/0000-0002-2513-502X

Lin Li

Sichuan Provincial People's Hospital: Sichuan Academy of Medical Sciences and Sichuan People's Hospital

\section{Research}

Keywords: Breast cancer, Interferon y, Loranthus micranthus, Indoleamine 2,3-dioxygenase

Posted Date: October 16th, 2020

DOI: https://doi.org/10.21203/rs.3.rs-90748/v1

License: (c) (i) This work is licensed under a Creative Commons Attribution 4.0 International License.

Read Full License 


\section{Abstract}

Background: Loranthus micranthus (African mistletoe) is a woody parasitic plant. It is found in Africa, Asia, Europe, and America. Its leaves and stem/twigs have been used in traditional medicine in various continents for the treatment of metabolic diseases: diabetes, hypertension, and cancer. The present study is designed to investigate the effect of Loranthus micranthus leaves and stem (LML and LMS) extracts on indoleamine 2,3-dioxygenase (IDO); a key regulator of cancer immunity; and the possible molecular mechanism(s) involved.

Methods: Human breast cancer cells; MDA MB-231 and MCF-7 were pre-treated with LML and LMS at doses of $1-30 \mu \mathrm{g} / \mathrm{mL}$ for 2 hours. This was followed by interferon-y (INF- $\gamma$ ) stimulation at $50 \mathrm{ng} / \mathrm{mL}$ for 24 hours. After the treatment period, the activity of indoleamine 2,3 dioxygenase 1 (ID0-1) and T cell proliferation were determined using a spectrophotometric assay. Protein expression of ID0-1, ID0-2, tryptophan-2,3-dioxygenase-2 (TDO-2), Bridging inhibitor 1 (BIN-1), Janus kinase/signal transducers and activators of transcription (JAK/STAT), Inhibitor of $\mathrm{k} B(\mathrm{IKBa})$ and Nuclear factor-KB (NF-KB) pathway were analyzed using the western blotting technique. The mRNA expression of IDO-1 was quantified using the qRT-PCR technique.

Results: MDA MB-231 and MCF-7 cells pre-treated with LML and LMS exhibited lower kynurenine synthesis than that of INF-y treatment. We observed downregulation of ID 0-1, ID 0-2, and TD 0-2 protein expressions, and lower IDO-1 catalytic activity in LML and LMS pretreated cells than those of INF- $Y$ treated cells alone. Cells pretreated with LML and LMS exhibited significant downregulation of phosphorylation of JAK-1, JAK-2, STAT-1, and STAT-3 than those of IFN-y treatment alone. Furthermore, LML and LMS pre-treated cells exhibited upregulation of IKBa and BIN-1 protein expression compared with IFN- $y$ treated cells alone. Additionally, LML and LMS pretreatment significantly improved T cell viability when compared with IFN- $y$ treated cells alone.

Conclusion: These findings indicate that LML and LMS extracts regulate immune responses in cancer cells by inhibiting IDO activity/expression in a JAK/STAT and NF-KB-dependent manner. This accounts for their anticancer effects in traditional medicine, hence a promising candidate for future drug development.

\section{Background}

Humans are endowed with myriads of medicinal remedies from nature's treasure chest of green gold (herbs). Herbal products and their derivatives have been reported to represent more than $50 \%$ of the drugs in modern therapeutics [1]. Since ancient times, research and development of therapeutic agents have focused on drug discovery from herbal medicines or botanical sources [2]. This is because synthetic agents have more intense adverse effects than the natural/plant agents [3]. Thus, some plant-derived drugs such as vincristine, vinblastine, Paclitaxel (Taxol), Myriocin among others have been introduced for the treatment/management of cancer and various ailments [4]. 
Loranthus micranthus (African mistletoe) belongs to the family of Loranthaceae, and is used in Nigerian folklore medicine as immune-enhancer and antioxidant especially in some of the immuno-related pathological diseases including but not limited to cancer, diabetes, flu and other viral infections [5]. Earlier studies demonstrate preliminary scientific evidence for this practice [6]. Several experimental shreds of evidence demonstrating anticancer potentials of mistletoe plant extract from different continents have been reported $[7,8,9,10,11,12]$. However, there is no report linking mistletoe's pharmacological effects to indoleamine 2,3 dioxygenase and kynurenine pathways. Following preliminary scientific evidence and traditional healing claims of Loranthus micranthus; its phytoconstituents have been structurally elucidated $[5,10,13]$. The various compounds, like quercetin, rutin, and epicatechin identified in this plant are known to possess anti-inflammatory, antioxidant, antitumor and immunomodulatory properties principally by regulating immune cell proliferation $[5,10,13]$. Although Immunomodulatory activity of Loranthus micranthus on mice splenocyte, was reported by Ogechukwu et al. 2011; studies on the molecular mechanisms linking the immunomodulatory potentials of this plant to IDO regulation remain to be clarified. Hence the need for the current study.

Studies on genetic and pharmacological assessment of IDO and TDO have confirmed that this tryptophan metabolism enzymes are a central driver of immunologic processes including autoimmunity, cancer growth/advancement, diabetes among others [14, 15]. The catabolic metabolite of the IDO enzyme- kynurenine, has received increasing attention owing to its link with inflammation, the immune system, cancer progression and neuro-toxicological conditions $[15,16]$. To this end, therefore, this study for the first time designed to evaluate the possible effects of Loranthus micranthus leave and stem (LML and LMS) extracts on IDO expression, is very important to further understand the underlying mechanisms of its therapeutic influence particularly in autoimmune disorders like cancer, and the need for future drug development from its Phytoconstituents.

\section{Materials And Methods}

\section{Chemicals and Reagents}

Antibodies used for this study and their sources are as follows: IDO 1 \#13268-I-AP, IDO 2 \#25053-1-AP, TDO 2 \#15880-I-AP, BIN 1 \#15880-I-AP, JAK 2 \#17670-1-AP, and IKB-a \#10268-1-AP, were purchased from Proteintech, San Ying Biotechnology, Wuhan, China. JAK 1 (3332S), and p-JAK 2 (3776S), from Cell Signaling Technology. STAT 1 (ET1606-39), and STAT 3 (ET1607-38) from HangZhou HuaAn Biotechnology Co., Ltd. p-JAK 1 \#11149-1, Tyr 1022, p-STAT 1 \#11044, Tyr 701, p-STAT 3 \#11045, Tyr 705, and NFkB-p65 \#21014, from Signalway antibody, Baltimore Ave. USA. IDO 1 primers were obtained from Bioengineering (Shanghai) Co., Ltd. Interferon- $\gamma$ was obtained from GenScript Piscataway, NJ USA. Nylon wool fiber for T-cell purification (\#18369-10) from Polysciences, Inc. Warrinton PA. USA. Every other chemicals and solvents were purchased from Sigma-Aldrich. Reagents used in this study were of the highest available analytic grade (purity $\geq 98 \%$ ).

\section{Authentication of Plant Material}


LML and LMS, collected from trees around the eastern part of Nigeria, in July 2017, authenticated by the Department of Botany herbarium team, the University of Ibadan, where a voucher specimen exists in the herbarium (UIH-22812). Subsequently, leaves (LML) and stem (LMS) were separated, air-dried in a room protected from light.

\section{Preparation of plant Extract}

Dried leaves and stem, were crushed separately in an electric grinder. From the powder of LML and LMS: $10 \mathrm{~g}$ was extracted with $100 \mathrm{~mL}$ of $75 \%$ aqueous ethanol by maceration for 48 hours at $25^{\circ} \mathrm{C}$. The extract was filtered, and dried by low pressure, and stored at $4^{\circ} \mathrm{C}$, protected from light.

\section{HPLC Analysis of Extract}

According to the method described by Vijay et al. [17] with slight modification as described in brief; $10 \mathrm{mg}$ of powdered plant extracts of LML and LMS were dissolved in $10 \mathrm{~mL}$ of methanol to get a concentration of $1 \mathrm{mg} / \mathrm{mL}$, subsequently, the solution was filtered using a $0.45 \mu \mathrm{m}$ syringe filter (Millipore) for sterilization. $1 \mathrm{mg}$ of each standard (epicatechin, quercetin, and rutin) was dissolved individually in $1 \mathrm{~mL}$ of methanol and sterile filtered through $0.45 \mu \mathrm{m}$ syringe filter (Millipore), before HPLC analysis. The prepared samples of extracts and standards were used for HPLC. The SSI 1500 HPLC series equipped with a DAD detector connected to the system processor was used for analysis. The system explored Empower software with standard certification for analysis of the results; maximum pressure of 2500 psi and a minimum of 1500 psi was maintained. The HPLC of solvents (60:40 ratio of methanol and water) was run at $300 \mathrm{~nm}$ wavelength using reverse phase $\mathrm{C}-18$ column $(5 \mu \mathrm{m}, 250 \mathrm{~mm}$ X $4.6 \mathrm{~mm})$. During the run, a flow rate of $1 \mathrm{~mL} / \mathrm{min}$ was maintained using a binary mode of gradient system. To, identity the compounds, standards of epicatechin, quercetin, and rutin were used. The peaks were identified by comparing the retention time (RT) of the standard with that of different peaks obtained in HPLC analysis of extracts confirmed by UV-spectra online.

\section{Enzyme assay for ID01 activity}

MDA-MB 231 and MCF-7 cells were seeded in a 96-well plate $\left(1 \times 10^{5}\right.$ cells/well) and treated with LML and LMS doses of $1 \mu \mathrm{g} / \mathrm{mL}, 5 \mu \mathrm{g} / \mathrm{mL}, 10 \mu \mathrm{g} / \mathrm{mL}, 15 \mu \mathrm{g} / \mathrm{mL}, 20 \mu \mathrm{g} / \mathrm{mL}$ and $30 \mu \mathrm{g} / \mathrm{mL}$ for $2 \mathrm{~h}$ before addition of INF-y $(50 \mathrm{ng} / \mathrm{mL})$ for another $24 \mathrm{~h}$ to determine the $\mathrm{IC}_{50}$. Dimethylsulfoxide (DMSO, 0.5\%) and epacadostat $(25 \mathrm{nM})$ were used as negative and positive controls respectively. ID01 activity was estimated by measuring the concentration of L-kynurenine in cell culture media according to the method described by Travers et al. [18]. In Brief; $100 \mu \mathrm{L}$ of culture medium was incubated with IDO buffer and then mixed with $25 \mu \mathrm{L}$ of $30 \%$ trichloroacetic acid, incubated for 30 minutes at $50{ }^{\circ} \mathrm{C}$ and thereafter centrifuged at $10,000 \mathrm{rpm}$ for $5 \mathrm{~min} .100 \mu \mathrm{L}$ of the supernatant was transferred into a new 96 well plate, and an equal volume of freshly prepared $2 \% \mathrm{w} / \mathrm{v} p$-dimethylaminobenzaldehyde in acetic acid was added. The optical density was measured at $480 \mathrm{~nm}$ using Thermo Scientific VarioskanFlash Multimode Reader. The kynurenine concentration was determined from L-kynurenine standard curve. Each assay was performed in triplicate and data presented as mean \pm standard error of mean. 


\section{Cell viability assay}

MDA-MB 231 and MCF-7 cells were seeded in a 96-well plate $\left(1 \times 10^{5}\right.$ cells/well $)$ and treated with LML and LMS doses of 1, 5, 10, 15, 20 and $30 \mu \mathrm{g} / \mathrm{mL}$ for $2 \mathrm{~h}$. INF-y $(50 \mathrm{ng} / \mathrm{mL})$ was added for another $24 \mathrm{~h}$ at $37^{\circ} \mathrm{C}$ in a humidified incubator with $5 \% \mathrm{CO}_{2}$, to determine the cell viability. Dimethylsulfoxide (DMSO, $0.5 \%)$ and epacadostat $(25 \mathrm{nM})$ were used as negative and positive controls respectively. The cell viability was determined by replacing the initial culture medium with $100 \mu \mathrm{L}$ of fresh culture medium containing $10 \%$ of the Cell Counting Kit-8 (CCK-8, Beyotime) in each well of the microplate. After 1 hour of incubation at $37^{\circ} \mathrm{C}$ in a humidified incubator with $5 \% \mathrm{CO}_{2}$, the absorbance was read at $450 \mathrm{~nm}$ on a Thermo Scientific VarioskanFlash Multimode Reader. Cell viability was calculated as a percentage of control (DMSO, 0.5\%).

\section{Western blotting}

Cells were harvested in RIPA buffer supplemented with a protease inhibitor cocktail (Sigma, Shanghai, China) at the end of the treatment period. The concentration of protein was measured by using a BCA protein assay kit (Bestbio, Shanghai, China). Western blotting was conducted according to standard procedures, as described in our earlier study, Wonganan et al. [19]. In brief; well-mixed aliquots of total cell lysates with loading buffer were boiled for 3-5 min, and separated on a $10 \%$ sodium dodecyl sulfate (SDS)-polyacrylamide gel. After electrophoresis, gels were cut according to molecular weight with the aid of Blue Plus ${ }^{\circledR}$ II Protein Marker (TransGen Biotech Co., LTD Cat. No. DM111-01) and proteins were transferred to nitrocellulose membranes and $5 \%$ bovine serum albumin or $5 \%$ defatted milk powder were used to block for $1 \mathrm{~h}$ at room temperature and then incubated overnight at $4{ }^{\circ} \mathrm{C}$ with each of the following antibodies: anti-ID01, anti-ID02, anti-TD02, anti-BIN1, anti-phospho-STAT1, anti-STAT1, anti-phosphoSTAT2, anti-STAT2, anti-phospho-STAT3, anti-STAT3, anti-NFKB-p65, anti-IkB-a and GAPDH across all gel for each protein. Afterward, the membranes were incubated with an appropriate peroxidase-conjugated secondary antibody 511203 (Zen Bioscience, Chengdu). The protein bands were determined by the detection of enhanced chemiluminescence solution (Amersham Biosciences, Piscataway, NJ, USA).

\section{Evaluation of ID01 activity/expression in pCMV3-ID01-transfected HEK293A cells}

HEK293A cells were seeded in a 6-well plate, overnight for proper attachment. pCMV3-ID01 plasmids $(0.94 \mu \mathrm{g} / \mu \mathrm{L})$ were transfected into cells by using lipofectamine ${ }^{\circledR} 2000$ according to the manufacturer's instructions. After $6 \mathrm{~h}$ of incubation, the transfection complex was replaced with fresh medium, and the transfected cells were used for subsequent experiments $12 \mathrm{~h}$ later. Transfected cells were treated with different concentrations of LML and LMS (5, 10 and $20 \mu \mathrm{M})$ and epacadostat $(25 \mathrm{nM})$ served as a positive control. After $2 \mathrm{~h}$ of incubation, the transfected and treated cells were lysed with RIPA lysis buffer, and IDO 1 activity was estimated while the same amount of protein samples were separated on SDSPAGE to determine the ID01 expression by Western blot analysis.

\section{Quantitative real-time reverse transcription-polymerase chain reaction (qRT-PCR)}


Total cellular RNA isolated from treated MDA-MB 231 and MCF-7 cells using TRIzol reagent (Invitrogen) by following the manufacturer's protocol was reverse-transcribed using SuperScript III Reverse Transcriptase (Invitrogen) with oligo dT18 primer. Equal amounts of cDNA were subjected to real-time quantitative PCR with the fluorescent dye SYBR Green I by following the manufacturer's protocol (TransGen Biotech, Beijing, China). The primer pairs used in the assay for IFN-y induced IDO 1 and glyceraldehyde-3-phosphate dehydrogenase (GAPDH) were as follows: IDO 1, (forward); 5'-AA C AGC GCC TTT AGC AAA GTG TCC CGT TCT TG-3' (reverse); 5'-AGC GCC TTG CAC GTC TAG TTC TGG GAT GC-3' and GAPDH, (forward); 5'-TGC ACC ACC AAC TGC TTA GC-3', (reverse); 5'-GGC ATG GAC TGT GGT CAT GAG-3'. The samples were run in triplicate and the relative expression levels of IDO 1 were determined by normalizing the expression of each target gene to that of IFN- $\gamma$ using the $2-{ }^{\Delta \Delta C t}$ method.

\section{Co-culture and T cell Proliferation Assay}

Primary T cells were isolated from mouse spleen by following the method described by Flaherty and Reynolds [20], with little modifications as follows in brief: Spleens from freshly sacrificed mouse were collected into a $60 \mathrm{~mm}$ dish containing $3 \mathrm{ml}$ of PBS+. Afterward, a square of sterile nylon mesh was placed over the tissue using sterilized forceps. The thumb side of a syringe plunger (3-10 mL) was used to gently smash the tissue against the mesh. This was followed by pipetting the suspension up and down a few times to break up the remaining soluble clumps and a new square piece of nylon mesh was placed over the opening of a $15 \mathrm{~mL}$ conical tube and the suspension filtered through to remove the remaining debris of splenic tissues. Cells were centrifuged at $475 \mathrm{xg}$ for $5 \mathrm{~min}$ at $4^{\circ} \mathrm{C}$, then the supernatant discarded and re-suspend the cell pellet in $1 \mathrm{~mL}$ of ice-cold $1 \mathrm{X}$ cell lysing solution per spleen for $1 \mathrm{~min}$ to lyse erythrocytes. Then $10 \mathrm{ml}$ of $\mathrm{PBS}^{+}$was added on top of the lysing solution, and the tube inverted twice, and centrifuged at $475 \mathrm{xg}$ for $5 \mathrm{~min}$ at $4^{\circ} \mathrm{C}$. After centrifugation, the supernatant (splenocytes) was aspirated and re-suspended in another $10 \mathrm{~mL}$ of $\mathrm{PBS}^{+}$. Primary $\mathrm{T}$ cells from the splenocytes were purified by using nylon wool mesh (Polysciences, Inc. USA).

MDA MB-231 cells were incubated with T-Cells isolated from mice as described above. Cancer cells were incubated with T-cells at a ratio of $1: 10$ or $1: 5$ (cancer cells: T-Cells) for $48 \mathrm{~h}$ at $37^{\circ} \mathrm{C}$ in a humidified incubator with $5 \% \mathrm{CO}_{2}$. At the end of co-culture experiments, conditioned medium (Dulbecco's Modified Eagle Medium (DMEM) plus 10\% Fetal Bovine Serum (FBS) was discarded by pipetting, and cell viability was estimated using CCK 8 counting kit as described above.

\section{Statistical Analysis}

Statistical analysis was performed with GraphPad Prism 5.0 software (GraphPad, La Jolla, CA, USA). Experiments were repeated at least three times and representative results presented. The data were compared by the Student- $T$ test for each concentration of LML and LMS and one-way ANOVA across the groups followed by Dunnett's post-hoc test. Differences were considered statistically significant for values at $p<0.05$. 


\section{Results}

\section{HPLC analysis of LML and LMS extracts}

Earlier study by Omeje et al. [5] indicated that flavonoids like epicatechin, rutin and quercetin were present in the plant (LML and LMS) extracts. The HPLC analysis of LML and LMS in the current study confirmed the presence of epicatechin, rutin and quercetin in both LML and LMS extracts as shown in Fig. $1 \mathrm{~A}$, and $1 \mathrm{~B}$.

\section{Effects Of Lml And Lms Extracts On Kynurenine Synthesis}

To examine the effect of LML and LMS extracts on kynurenine synthesis; breast cancer cells were incubated with various concentrations $(5,10$ and $20 \mu \mathrm{g} / \mathrm{mL})$ of LML and LMS for $2 \mathrm{~h}$. This was followed by addition of INF- $\mathrm{Y}(50 \mathrm{ng} / \mathrm{mL})$ and incubated for $24 \mathrm{~h}$. As shown in Fig. 2A and 2D; IFN- $\gamma$ induced kynurenine synthesis in MDA MB-231 and MCF-7 cells were significantly inhibited by Epacadostat (a specific inhibitor of ID01 activity). Additionally, both LML and LMS at 5-20 $\mu \mathrm{g} / \mathrm{mL}$ also significantly inhibited IFN-y induced kynurenine synthesis in both breast cancer cells. To examine the effect of extracts on kynurenine synthesis in more detail; breast cancer cells were treated with LML and LMS at concentrations of 1 to $30 \mu \mathrm{g} / \mathrm{mL}$ as shown in Fig. 2B and 2E. LML and LMS extracts inhibited kynurenine synthesis in a concentration-dependent manner in MDA MB-231 and MCF-7 cells. The IC $\mathrm{I}_{50}$ values for LML and LMS extract were calculated as 4.05 and $12.13 \mu \mathrm{g} / \mathrm{mL}$ in MDA-MB 231 cells and 10.7 and $8.9 \mu \mathrm{g} / \mathrm{mL}$ in MCF-7 cells respectively. The cut-off limit for relative cell viability for cytotoxicity is $50 \%$; therefore, tested concentrations of LML and LMS were not cytotoxic to MDA MB-231 and MCF-7 cells (Fig. $2 \mathrm{C}$ and $2 \mathrm{~F}$ ). These findings indicate that $\mathrm{LML}$ and $\mathrm{LMS}$ extracts inhibit kynurenine synthesis in breast cancer cells.

\section{Influence Of Lml And Lms Extracts On Ido Expression/activity}

Furthermore, we examined whether LML and LMS have efficient inhibitory effects on ID01, IDO2 and TD02 expression following IFN- $\gamma$ stimulation in MDA-MB 231 and MCF-7 cells. Pre-treated cells particularly at 10 and $20 \mu \mathrm{g} / \mathrm{mL}$ of extracts exhibited a lower ID01, IDO2 and TD02 protein expression compared with IFN- $y$ treated cells alone as shown in Figs. 3A, B, C and D. Furthermore, INF- $\gamma$ induced IDO 1 mRNA expression in MDA MB-231 and MCF-7 cells were significantly suppressed by LML and LMS pretreatment (Figs. 3E, F, G and H). These results indicate that, treatment with extracts inhibit INF-y induced IDO expression at the transcriptional level. To further investigate whether LML and LMS extracts possess direct inhibitory activity on ID01 protein; ID01 was transiently over-expressed in HEK293A cells. As shown in Figs. $3 \mathrm{I}$ and J; LML and LMS extracts significantly inhibited relative IDO 1 catalytic activity in ID01overexpressing HEK293A cells, indicating that the extracts also directly inhibit the catalytic activity of 
ID01. These findings suggest that extracts inhibit kynurenine synthesis in cancer cells by the suppression of ID01 catalytic activity and its expression both at the translational and protein levels. Figures $3 \mathrm{~K}$ and $\mathrm{L}$ showed no effect on IDO 1-overexpressing HEK 293A confirming the direct inhibitory effect on the catalytic activity and not degradation of IDO 1 protein.

\section{Influence Of Lml And Lms Extracts On Jak/stat Pathway}

To further expound the molecular mechanism controlling the suppression of IDO expression by LML and LMS; JAK/STAT signaling pathway was evaluated in MDA MB-231 cells. LML and LMS at 10 and $20 \mu \mathrm{g} / \mathrm{mL}$ pre-treated cells for 2 hour inhibited IFN- $\gamma$ phosphorylation of STAT1 and STAT3. Similarly, IFN- $\gamma$ induced-phosphorylation of JAK1 and JAK2 was also inhibited by LML and LMS pre-treatment at 10 and $20 \mu \mathrm{g} / \mathrm{mL}$ for 2 hour (Fig. 4A, B, C and D). There was remarkable inhibition in the cells treated with JAK inhibitor 1. These results suggest that LML and LMS extracts can suppress INF-y induced IDO expression via the inhibition of JAK/STAT pathway.

\section{Effects of LML and LMS extracts on NF-KB and BIN 1 expression}

As shown in Fig. 5A; INF-y induced downregulation of IKB-a expression was upregulated in MDA MB-231 cells by LML and LMS pre-treatment. Conversely, pre-treatment with LML and LMS at 10 and $20 \mu \mathrm{g} / \mathrm{mL}$ did not show noticeable change in the expression level of total NF-KB p65 compared with INF- $\gamma$ treated cells alone in MDA MB-231 cells. However, LML and LMS pre-treated cells exhibited augmentation in expression of BIN 1 relative to INF-y treated cells alone (Fig. 5B). These findings indicate that LML and LMS extracts suppress INF- $y$ induced IDO expression via the inhibition of NF-KB pathway and upregulation of BIN1.

\section{Effects of LML and LMS extracts on T cell viability}

To determine the possible influence of LML and LMS pre-treatment on T cell survival, we isolated primary T cells from the spleen of female C57 mice and co-cultured them with MDA MB-231 cells. As shown in Fig. 6; IFN- $y$ treatment of MDA MB-231 cells decreased the proliferation of T cells, whereas LML and LMS pre-treatment of MDA MB-231 cells significantly restored the proliferation of T cells to near control cells. These results indicate that suppression of INF-y induced IDO expression by LML and LMS pre-treatment in breast cancer cells, enhanced T cell survival.

\section{Discussion}

IDO is overexpressed in several human cancers, such as prostate, breast, brain, and hematologic malignancies [21, 22, 23]. The current study is consistent with earlier reports. However, pretreatment with LML and LMS suppressed both ID01 mRNA and protein expression. Additionally, pCMV3-ID01transfected HEK 293A cells also showed a decrease in ID01 catalytic activity following treatment with LML and LMS extracts. This is an indication that the extracts are directly interacting with ID01 protein. 
Interestingly, the corresponding suppression of IDO2 protein expression by LML and LMS treatment further increased the potentials of this plant to assuage compromised immune responses associated with cancer progression. The Previous report on detailed preclinical studies showed that epacadostat acts as a kynurenine/tryptophan-competitive inhibitor of the catabolic activity of human ID01 in cellbased assays. It was also observed that epacadostat showed no effect on ID01 protein expression [24, $25,26]$. The current study corroborated earlier report; epacadostat elicited no inhibitory effects on IDO1 protein expression. TRP metabolism is a substitute path to ID01 activity engaged by tumors. Hence, there is increasing interest in pharmacological targeting of TDO for cancer immunotherapy [27]. Interestingly this study revealed that LML and LMS pre-treatment elicited a significant inhibition in ID01, IDO2, and TD02 protein expressions, following IFN-y stimulation in the two breast cancer cells. These findings have further strengthened the earlier report on the immunomodulatory effects of the studied plant.

Induction of IDO expression by Inflammatory mediators such as IFN-y is mediated by JAK-STAT dependent mechanism(s) [28] and NFKB signaling pathways in cells [29]. The current findings revealed the influence of LML and LMS treatment in downregulating IDO expression by blocking the JAK-STAT and NFKB signaling pathways. This is in agreement with other reports that IDO downregulation is mediated by JAK/STAT and NFKB pathways [30]. BIN 1 is a cancer suppressor protein that controls the expression of IDO1 [31]. Suppression of BIN 1, a tumor suppressor gene in tumor cells correlates with the up-regulation of IDO expression [32]. In the current study, LML and LMS extracts up-regulated BIN 1 expression in breast cancer cells, compared with INF-y treatment alone.

Up-regulation of IDO has been implicated in cancer progression by blocking T-cell activation ultimately leading to T-cell death. Thus, there is a need for immunomodulatory agents targeting this enzyme [33], to enhance T-cell viability. Therefore, the suppression of L-kynurenine concentration by LML and LMS pretreatment, after IFN- $\gamma$ stimulation in MDA-MB 231 cells also contributed to the inhibition of IDO expression in this study. Hence resulting in the improved survival rate of primary $T$ cells. These findings indicate that LML and LMS exert immunomodulatory properties by inhibiting IDO activity/expression and thus boosting immune response. The earlier report highlighted the potentials of phytochemicals to assuage compromised immune responses associated with cancer progression and other immune-related diseases [34] and the current report has further supported the claims.

\section{Conclusion}

LML and LMS extract inhibited kynurenine synthesis in breast cancer cells. This was followed by suppressing the expression of ID01, IDO2, and TD02. The underlying mechanism involves direct and indirect interaction between extracts and ID01, blocking of JAK/STAT and NF-KB pathways. Having identified a novel immunosuppressive activity of this plant; a further study on the assessment of the various phytochemicals with the aim of finding a novel compound and to identify the components that are responsible for the IDO regulation is an ongoing study in our laboratory.

\section{Abbreviations}


IDO; Indoleamine 2, 3-dioxygenase, LML; Loranthus micranthus leaves, LMS; Loranthus micranthus stems, TDO; TRP-2,3-dioxygenase, IFN-ץ; Interferon- $\gamma$, JAK/STAT; Janus kinase/signal transducers and activators of transcription, NF-kB; Nuclear factor к B, ІкB-a; Inhibitor kappa B-a, BIN1; Bridging integrator 1.

\section{Declarations}

\section{Ethics approval and consent to participate}

All experiments with mice followed the regulations of Chinese Academy of Science guidelines for the care and use of Laboratory Animals and approved by the Institutional Animal care and use committee of Chengdu Institute of Biology, Chinese Academy of Science (protocol number: CIBCAS-2019-0139).

\section{Consent for publication}

All the participating authors read the manuscript and give consent for publication.

\section{Availability of data and materials}

Please contact the corresponding author for data request

\section{Competing interests}

The authors have no real or potential conflicts of interest to declare.

\section{Funding}

This work was supported by National Natural Science Foundation of China (Nos. 21861142007, 21672207), Chinese Academy of Sciences President's International Fellowship Initiative (Nos. 2018PB0017, 2015PB049), Science \& Technology Department of Sichuan Province (No.2016JZ0022), Biological Resources Programme, Chinese Academy of Sciences (KFJ-BRP-008), and the National New Drug Innovation Major Project of China (2018ZX09711001-001-006). The funding bodies provided financial support for the purchase and supply of materials and reagents for this research.

\section{Authors' contributions}

APE, GZ, LL, and WFconceptualized and designed the experiment; APE, TP, EMN, and ZZ performed the experiment; APE, and WF interpreted the results; APE, AAH and WF prepared the manuscript. All authors have agreed both to be personally accountable for the author's own contributions and to ensure that questions related to the accuracy or integrity of any part of the work.

\section{Acknowledgements}

We acknowledge the support by National Natural Science Foundation of China (Nos. 21672207, 21861142007), Chinese Academy of Sciences President's International Fellowship Initiative (Nos. 
2018PB0017, 2015PB049), Science \& Technology Department of Sichuan Province (No.2016JZ0022), the Biological Resource Network of Chinese Academy of Sciences (ZSTH-030), and the National New Drug Innovation Major Project of China (2018ZX09711001-001-006).

\section{Author details}

${ }^{1}$ Center for Natural Products Research, Chengdu Institute of Biology, Chinese Academy of Sciences, Chengdu 610041, P.R. China.

2 Department of Laboratory Medicine, Sichuan Academy of Medical Sciences \& Sichuan Provincial People's Hospital, Chengdu 610072, P.R. China

${ }^{3}$ Department of Chemistry/Biochemistry/Molecular Biology, Alex Ekwueme Federal University, NdufuAlike, P.O. Box 1010, Abakaliki, Nigeria.

${ }^{4}$ Chemistry Department, Cape Peninsula University of Technology, Bellville Campus, Bellville 7537, Western Cape, South Africa

\section{References}

1. Si-Yuan P, Shu-Feng Z, Si-Hua G, Zhi-Ling Y, Shuo-Feng Z, Min-Ke T, Jian-Ning S, Dik-Lung M, Yi-Fan $\mathrm{H}$, Wang-Fun F, Kam-Ming K. New perspectives on how to discover drugs from herbal medicines: CAM's outstanding contribution to modern therapeutics. Evid-Based Complementary Altern Med. 2013;62:7375.

2. Akshada AK, Rajendra CD, Chandrakant SM. Chapter 14 Pharmacognosy, in: Shagufta Perveen and Areej Al-Taweel, editor, Natural products in drug discovery. Intech Open press, Rijeka, 2019; 82860.

3. Bushra N, Aeysha S, Syeda LR. Comparison of medicinally important natural products versus synthetic drugs-a short commentary. Nat Prod Chem Res. 2017;6:1000308.

4. Veeresham C. Natural products derived from plants as a source of drugs. J Adv Pharm Technol Res. 2012;3:200-1.

5. Omeje EO, Osadebe PO, Nworu CS, Ama H, Abdessamad D, Esimone CO, Akira K, Proksch P. Steroids and triterpenoids from Eastern Nigeria mistletoe, Loranthus micranthus Linn. (Loranthaceae) parasitic on Kola acuminata with immunomodulatory potentials. Phytochem Lett. 2011;4:357-62.

6. Osadebe PO, Omeje EO. Comparative acute toxicities and immunomodulatory potentials of five Eastern Nigeria mistletoes. J Ethnopharmacol. 2009;126:287-93.

7. Holtskog R, Sandvig K, Olsnes S. Characterization of a toxic lectin in Iscador, a mistletoe preparation with alleged cancerostatic properties. Oncology. 1988;45:172-9.

8. Huang KC. Section III cardiovascular system. In: Huang KC, editor. The Pharmacology of Chinese Herbs. Boca Raton: CRC Press; 1993. pp. 89-91. 
9. Park JH, Chang KH, Heuyn KS. Cytotoxicity of heat-treated Korean mistletoe. Cancer Lett. 1998;126:43-8.

10. Moghadamtousi SZ, Hajrezaei M, AbdulKadir H, Zandi K. Loranthus micranthus (Linn): biological activities and phytochemistry. Evid-Based Complementary Altern Med. 2013;27:37-42.

11. Patel S, Panda S. Emerging roles of mistletoes in malignancy management. Biotechnology. 2014;4:13-20.

12. Elsyana V, Bintang M, Priosoeryanto BP. Cytotoxicity and antiproliferative activity assay of clove mistletoe (Dendrophthoe pentandra (L.) Miq.) leaves extracts. Adv Pharmacal Sci. 2016; 3242698.

13. Ogechukwu OE, Ogoamaka OP, Sylvester NC, Kawamura A, Proksch P. Immunomodulatory activity of a lupane triterpenoid ester isolated from the eastern Nigeria mistletoe, Loranthus micranthus (Linn). Asian Pac J Trop Biomed. 2011;4:514-22.

14. Zhang P, Jiang G, Gao J, Li L, Du J, Jiao X. SAHA down-regulates the expression of indoleamine 2,3dioxygenase via inhibition of the JAK/STAT1 signaling pathway in gallbladder carcinoma cells. Oncol Rep. 2013;29:269-75.

15. Prendergast GC, Smith C, Thomas S, Mandik L, Laury NL, Metz KR, Muller AJ. Indoleamine 2,3dioxygenase pathways of pathogenic inflammation and immune escape in cancer. Cancer Immunol Immunother. 2014;63:721-35.

16. Levina V, Su Y, Gorelik E. Immunological and nonimmunological effects of indoleamine 2,3dioxygenase on breast tumor growth and spontaneous metastasis formation. Clin Dev Immunol. 2012;17:300-29.

17. Vijay L, Bhatia AK, Anjana G, Nitin W, Anubhuti S. Phytochemicals screening and analysis using HPLC to determine the antimicrobial efficacy of Cassia fistula extract. Adv Biores. 2015;6:1-7.

18. Travers MT, Gow IF, Barber MC, Thomson J, Shennan DB. Indoleamine 2,3-dioxygenase activity and L-tryptophan transport in human breast cancer cells. Biochim Biophys Acta. 2004;1661:106-12.

19. Wonganan O, He Y, Shen X, Wongkrajang K, Suksamrarn A, Zhang G, Wang F. 6-Hydroxy-3-0-methylkaempferol 6-0-glucopyranoside potentiates the anti-proliferative effect of interferon $\alpha / \beta$ by promoting activation of the JAK/STAT signaling by inhibiting SOCS3 in hepatocellular carcinoma cells. Toxicol Appl Pharmacol. 2017;336:31-9.

20. Flaherty S, Reynolds JM. Mouse naïve CD $4+\mathrm{T}$ Cell isolation and In vitro differentiation into T Cell subsets. J Vis Exp. 2015;98:527-39.

21. Uyttenhove C, Pilotte L, Theate I. Evidence for a tumoral immune resistance mechanism based on tryptophan degradation by indoleamine 2,3-dioxygenase. Nat Med. 2003;9:1269-74.

22. Lob S, Konigsrainer A, Rammensee HG, Opelz G, Terness P. Inhibitors of indoleamine 2,3dioxygenase for cancer therapy: can we see the wood for the trees? Nat Rev Cancer. 2009;9:445-52.

23. Ninomiya S, Narala N, Huye L, Yagyu S, Savoldo B, Dotti G, Helen EH, Brenner MK, Rooney CM, Ramos CA. Tumor indoleamine 2,3- dioxygenase (IDO) inhibits CD19-CAR T cells and is downregulated by lymphodepleting drugs. Blood. 2015;125:3905-16. 
24. George CP, William PM, James BD, Alexander JM. Discovery of ID01 Inhibitors: From bench to bedside. Cancer Res. 2017; 172-185.

25. Lauranne P, Rima A, Reece M, Bruno G, Jonathan S. Target exposure and pharmacodynamics study of the indoleamine 2,3-Dioxygenase-1 (IDO-1) inhibitor Epacadostat in the CT26 Mouse tumor model. J Pharm Biomed Anal. 2019; 12506.

26. Rong F, Yi-Wei Z, Hong-Mei L, Wen-Cong L, Li Z, Qing-Long G, Tao L, Stephen JW, Zhi-Yu L, Zhao-Qiu W. LW106, a novel indoleamine 2,3-dioxygenase 1 inhibitor, suppresses tumor progression by limiting stroma-immune crosstalk and cancer stem cell enrichment in tumor microenvironment. $\mathrm{Br} \mathrm{J}$ Pharmacol. 2018;175:3034-49.

27. Platten M, Doeberitz NK, Oezen I, Wick W, Ochs K. Cancer immunotherapy by targeting ID01/TDO and their downstream effectors. Front Immunol. 2015;5:67-73.

28. Sarkar SA, Wong R, Hack SI, Moua O, Gill RG, Wiseman A, Davidson HW, Hutton JC. Induction of indoleamine 2,3-dioxygenase by interferon $\mathrm{Y}$ in human islets. Diabetes. 2007;56:72-9.

29. Yang JM, Rui BB, Chen C, Chen H, Xu TJ, Xu WP, Wei W. Acetylsalicylic acid enhances the antiinflammatory effect of fluoxetine through inhibition of NF-KB, p38-MAPK and ERK1/2 activation in lipopolysaccharide-induced Bv-2 microglia cells. Neuroscience. 2014;275:296-304.

30. Yu J, Wang Y, Yan F, Zhang P, Li H, Zhao H, Yan C, Yan F, Ren X. Noncanonical NF-kB activation mediates STAT3-stimulated IDO upregulation in myeloid-derived suppressor cells in breast cancer. J Immunol. 2014;193:2574-86.

31. Muller AJ, DuHadaway JB, Donover PS, Sutanto-Ward E, Prendergast GC. Inhibition of indoleamine 2,3-dioxygenase, an immunoregulatory target of the cancer suppression gene Bin1, potentiates cancer chemotherapy. Nat Med. 2005;11:312-9.

32. Jia Y, Wang H, Wang Y, Wang T, Wang M, Ma M, Duan Y, Meng X, Liu L. Low expression of Bin1, along with high expression of IDO in tumor tissue and draining lymph nodes, are predictors of poor prognosis for esophageal squamous cell cancer patients. Int J Cancer. 2015;137:1095-106.

33. Sun J, Yu J, Li H, Yang L, Wei F, Yu W, Liu J, Ren X. Upregulated expression of indoleamine 2, 3dioxygenase in $\mathrm{CHO}$ cells induces apoptosis of competent $\mathrm{T}$ cells and increases proportion of Treg cells. J Exp Clin Cancer Res. 2011;30:82-92.

34. Arumuggam N, Nei IA, Rupasinghe HPV. A Review: phytochemicals targeting JAK/STAT signaling and IDO expression in cancer. Phytother Res. 2015;29:805-17.

\section{Figures}



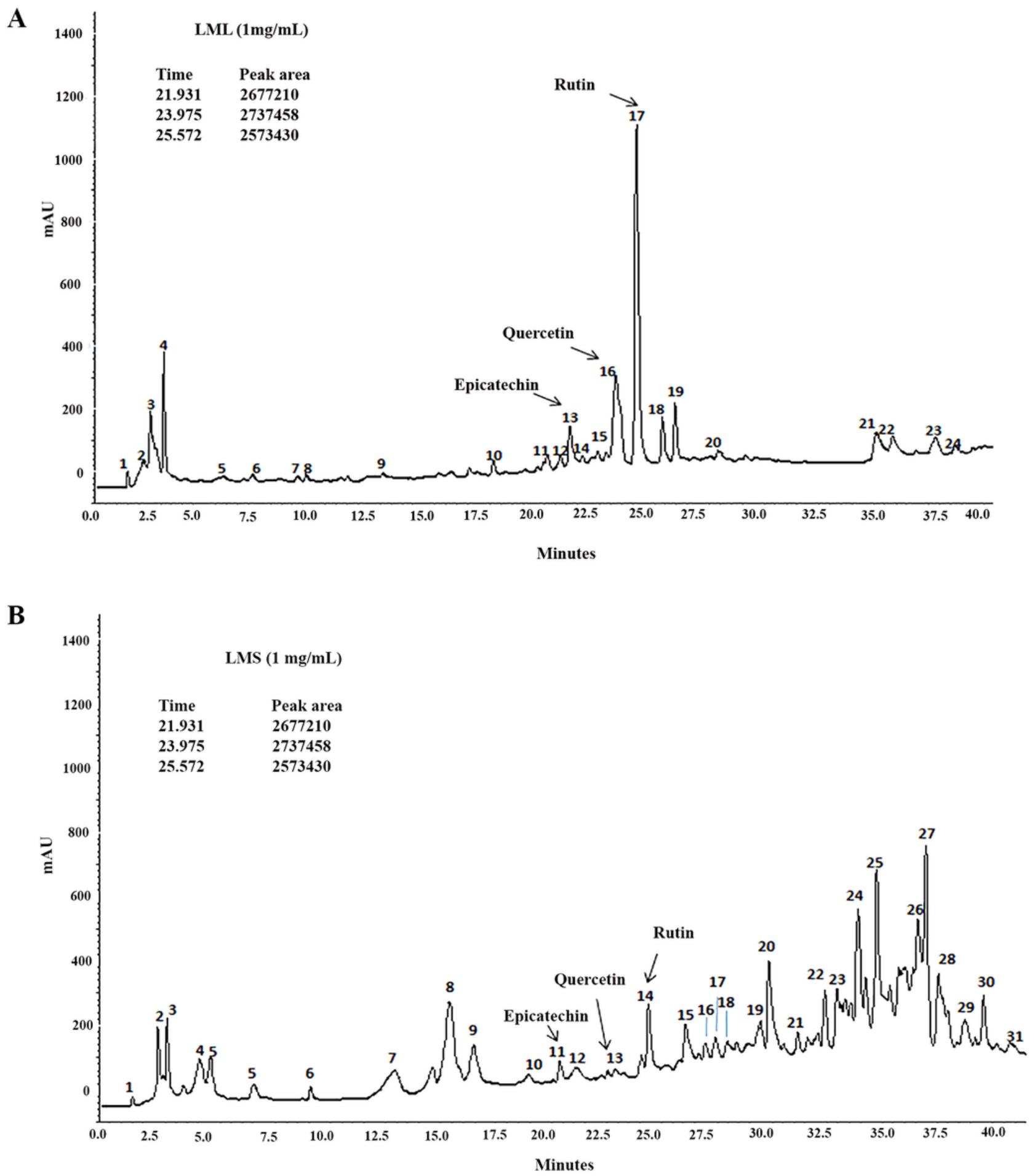

\section{Figure 1}

HPLC analysis of L. micranthus extracts. (A and B) represent the time and peak areas of the standards (Epicatechin, rutin and quercetin) against LML and LMS respectively. 
A

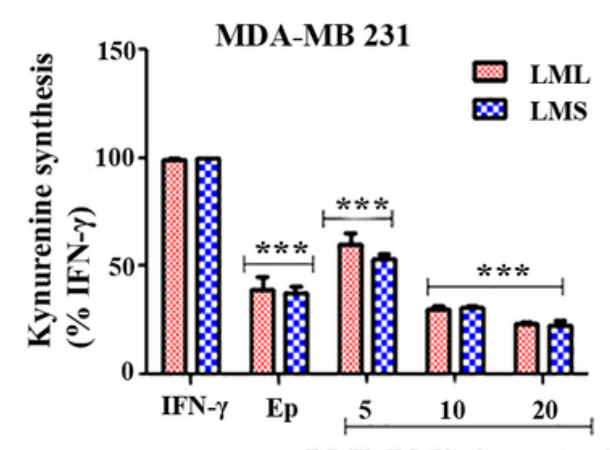

D

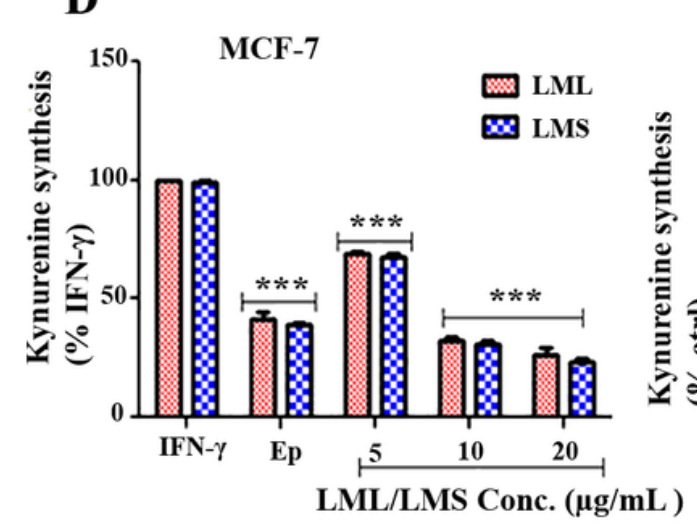

B

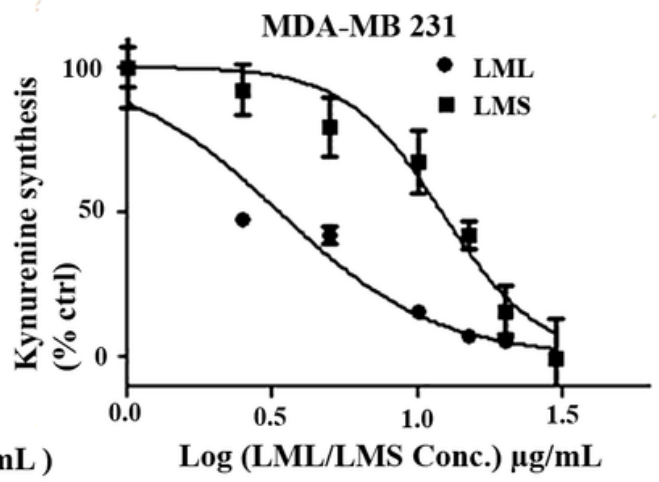

$\mathbf{E}$

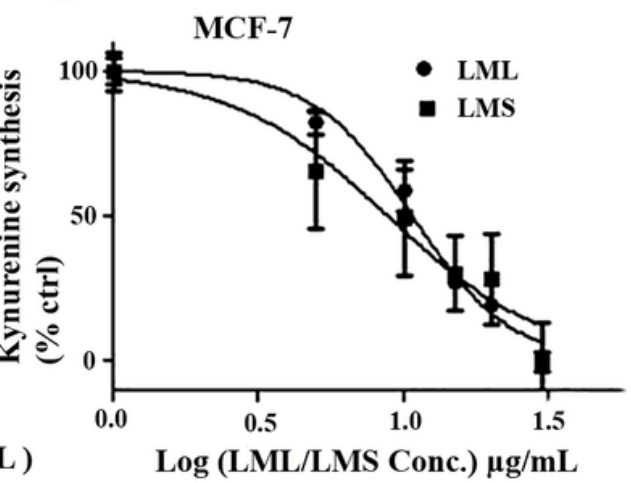

C
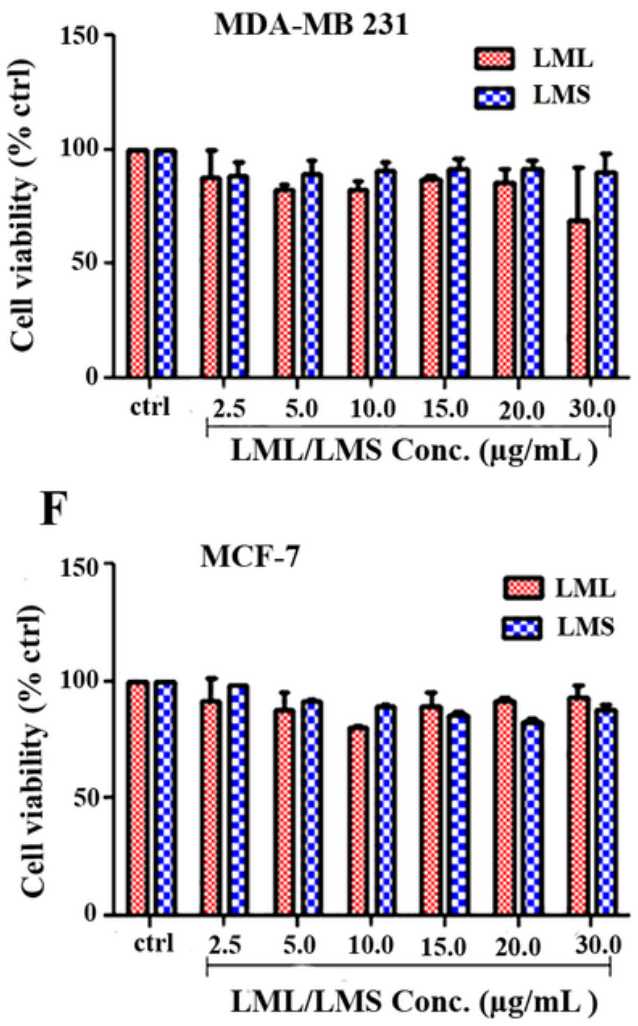

Figure 2

Effects of L. micranthus extracts on kynurenine synthesis in human breast cancer cells. MDA-MB 231 and MCF-7 cells were incubated with various concentrations of L. micranthus extracts for $2 \mathrm{~h}$ followed by addition of INF-Y $(50 \mathrm{ng} / \mathrm{mL})$ for another $24 \mathrm{~h}$. Epacadostat $(25 \mathrm{nM})$, a specific inhibitor of ID01, and DMSO served as positive and negative control respectively. (A and D) Represent MDA-MB 231 and MCF-7 cells pretreated with L. micranthus extracts at 5,10 and $20 \mu \mathrm{g} / \mathrm{mL}$ prior to INF- $\gamma$ stimulation, followed by evaluation of kynurenine synthesis in the two breast cancer cells. (B and E) Depict IC50 values for L. micranthus extracts on MDA-MB 231 and MCF-7 cells respectively. Their IC50 values were calculated as 4.05 and $12.13 \mu \mathrm{g} / \mathrm{mL}$ respectively for LML and LMS for MDA-MB 231 cells and 10.7 and $8.9 \mu \mathrm{g} / \mathrm{mL}$ respectively for LML and LMS for MCF-7 cells. ( $C$ and F) Represent the viability of MDA-MB 231 and MCF7 cells following LML and LMS pretreatment. $* \star *=p<0.001$ compared with the control $(n=3)$. 


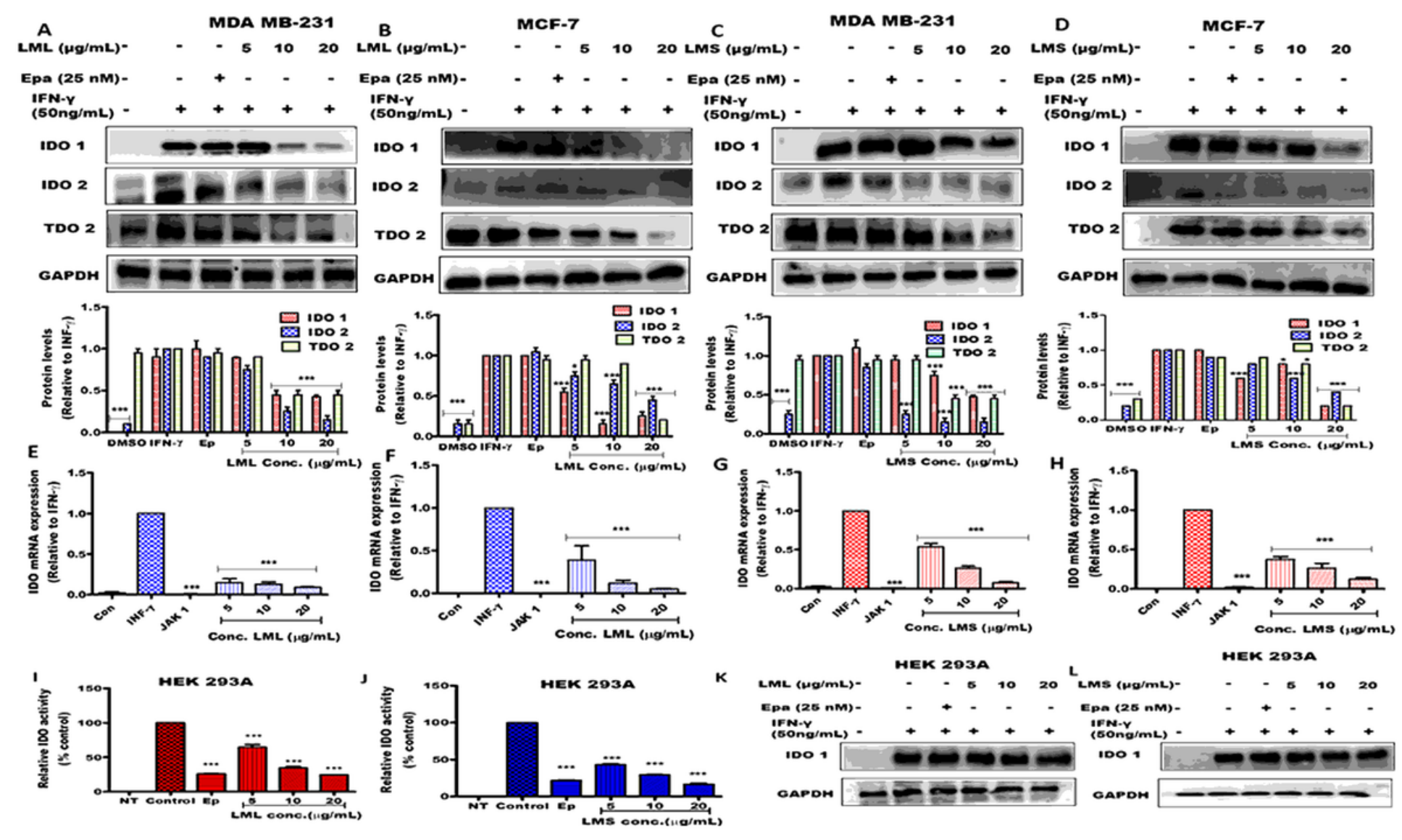

Figure 3

Influence of L. micranthus extract on IFN-y induced expression of IDO and TDO. (A, B, C and D) Represent protein expression of ID01, IDO2 and TDO2 following L. micranthus extracts pretreatment prior to induction by IFN- $\gamma$ in MDA-MB 231 and MCF-7 cells. (E, F, G and H) Illustrate the influence of L. micranthus extracts pretreatment on INF-y induced IDO 1 mRNA expression in both MDA-MB 231 and MCF-7 cells. (I, J, K and L) represent the influence of $L$. micranthus extracts on IDO 1 protein expression in pCMV3-ID01-transfected HEK 293 A cells. $* \star *=p<0.001$ compared with control $(n=3)$. 
A
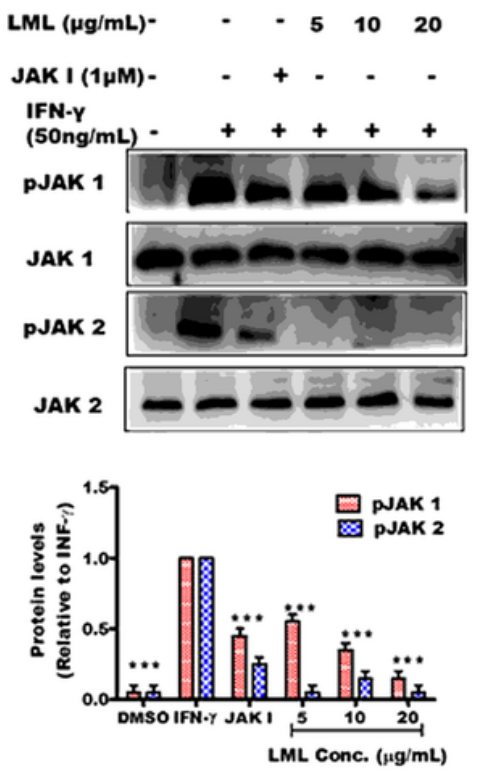

B

LMS $(\mu \mathrm{g} / \mathrm{mL})-\quad-\quad \begin{array}{lll}5 & 10 & 20\end{array}$

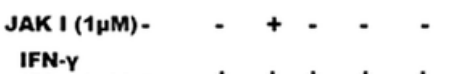

$(50 \mathrm{ng} / \mathrm{mL})-++++$

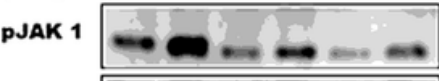

JAK 1

pJAK 2

JAK 2
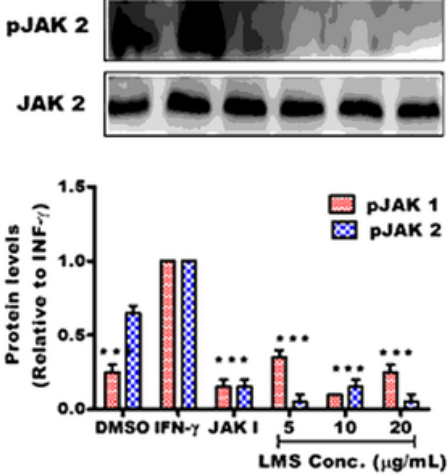

C

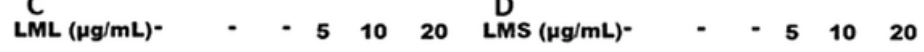

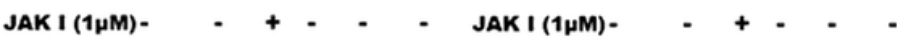

IFN-Y

$(50 \mathrm{ng} / \mathrm{mL})^{-}+++++\underset{(50 \mathrm{ng} / \mathrm{mL})}{-}+++++$
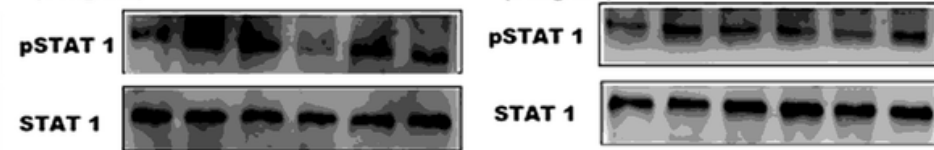

STAT 1

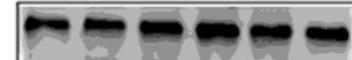

pSTAT $3=\ldots-\ldots-\ldots$ pSTAT 3

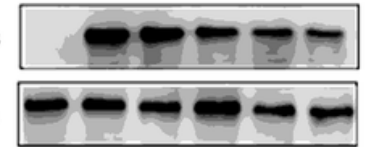

STAT 3

STAT 3

$\square$ PSTAT 1
PSTAT 3

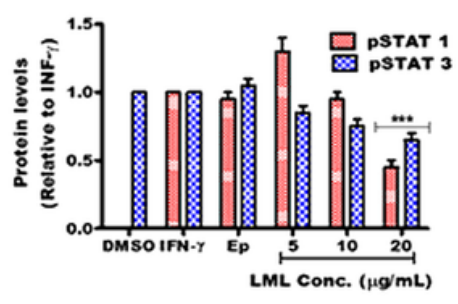

Figure 4

Influence of L. micranthus extract on JAK/STAT pathway. (A, B, C and D) Represent the effects of $L$. micranthus extracts on JAK/STAT pathway after IFN- $\gamma$ induction in MDA-MB 231 cells. $(n=3)$. 
A
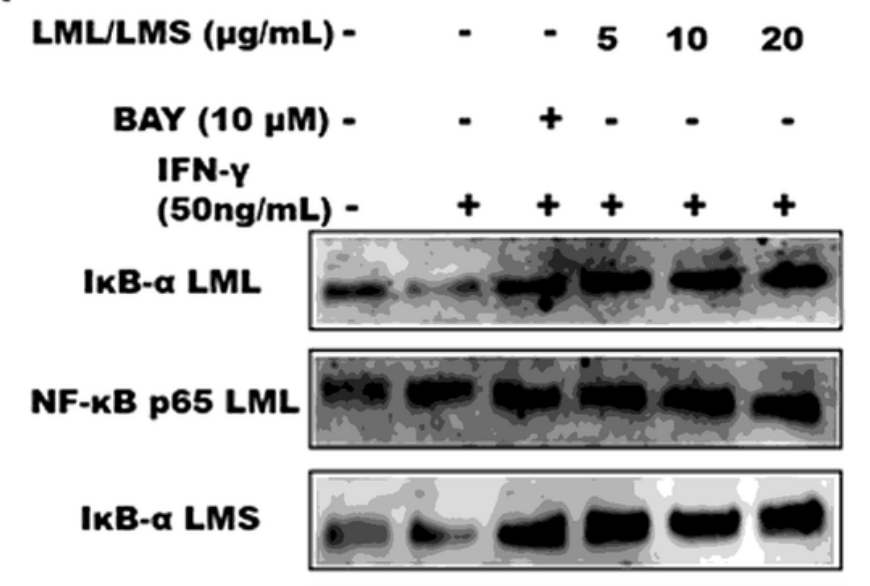

NF-kB p65 LMS
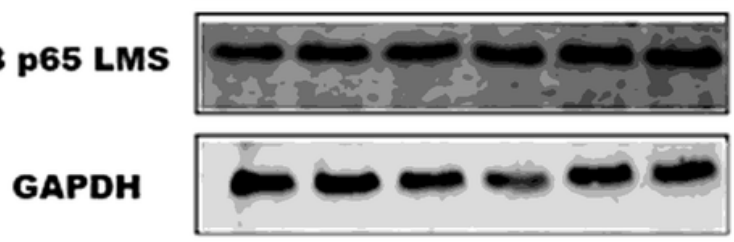

LML I×B- $\alpha$

$\mathbf{\infty}$ LMS I×B- $\alpha$

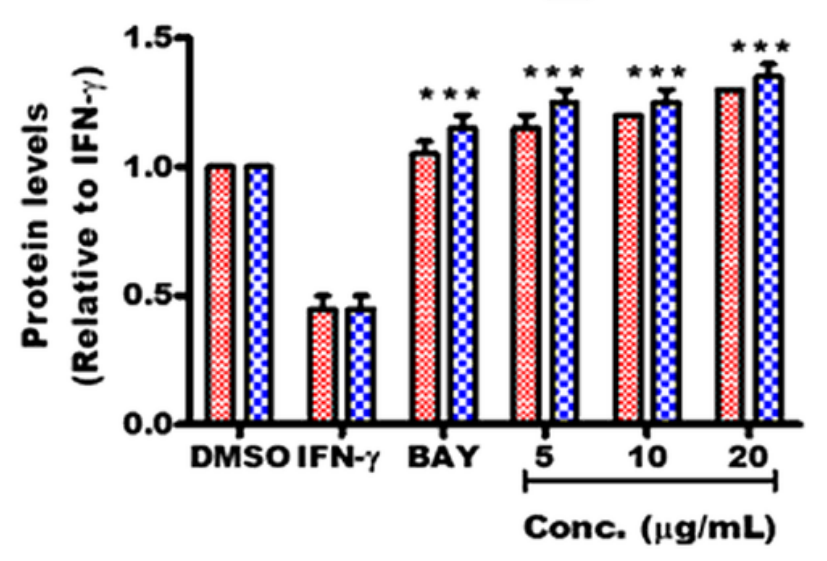

B

LML/LMS $(\mu \mathrm{g} / \mathrm{mL})-\quad \quad-\quad-\quad \begin{array}{lll}5 & 10 & 20\end{array}$

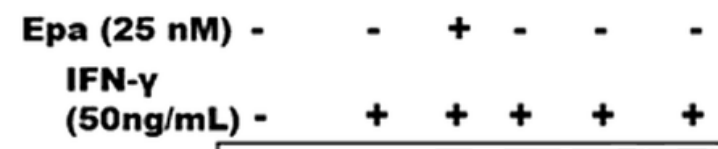

BIN 1 LML

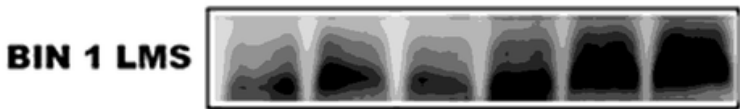

GAPDH
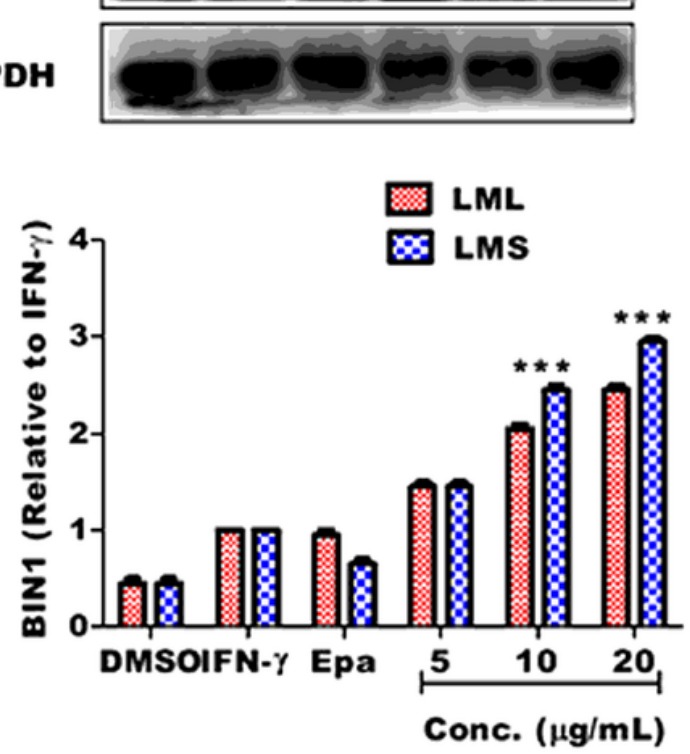

Figure 5

Influence of L. micranthus extract on IFN-y induced NFKB pathway. (A) Depicts the effects of $L$. micranthus extracts pretreatment on the expression of total NFKB and IKB- $a$ after INF- $\gamma$ stimulation in MDA-MB 231 cells. (B) Represents the effects of LML and LMS pretreatment on expression of BIN 1 after IFN- $y$ stimulation in MDA-MB 231 cells. ${ }^{\star * \star}=p<0.001$ compared with the control $(n=3)$. 

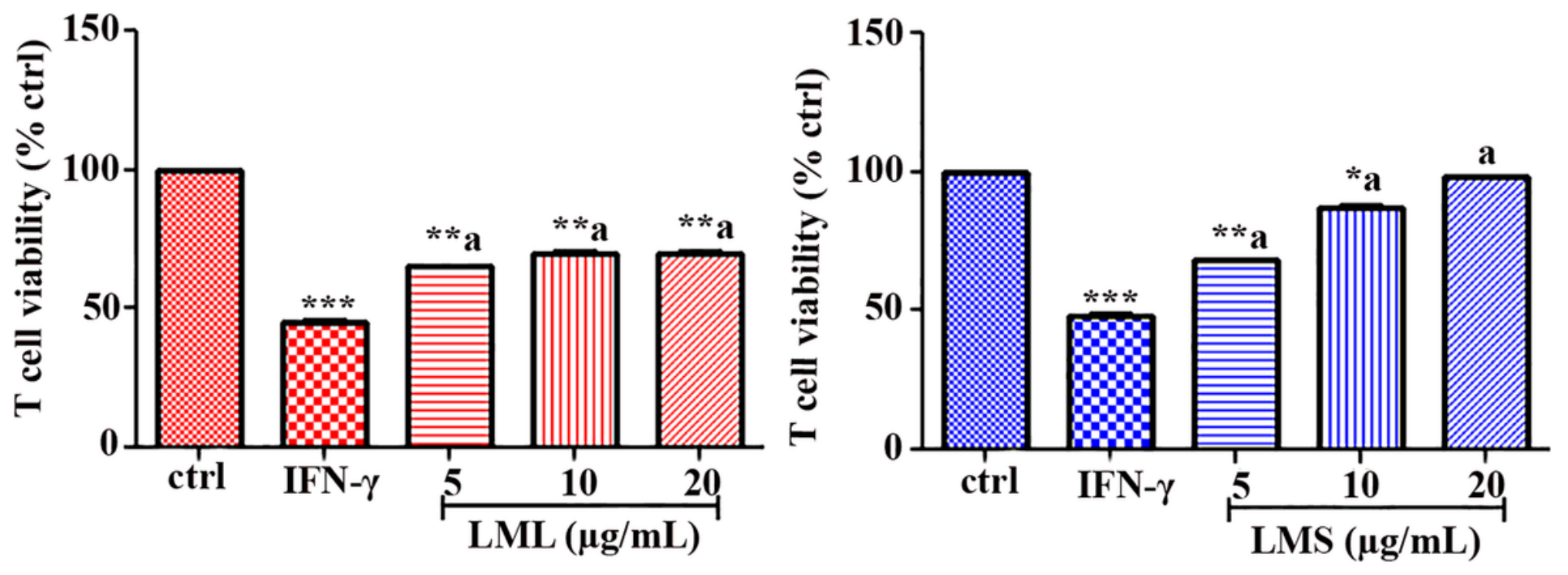

Figure 6

Effect of L. micranthus extracts on T-Cell viability. Isolated T cells from mouse were co-cultured with MDA-MB 231 cells, followed by L. micranthus extracts treatment. (A) Represents effects of LML treatment on T-cell viability. (B) Represents effects of LMS treatment on T-cell viability. ${ }^{\star \star \star}=p<0.001$ compared with control $(n=3) . a=p<0.05$ compared with IFN- $\gamma(n=3)$.

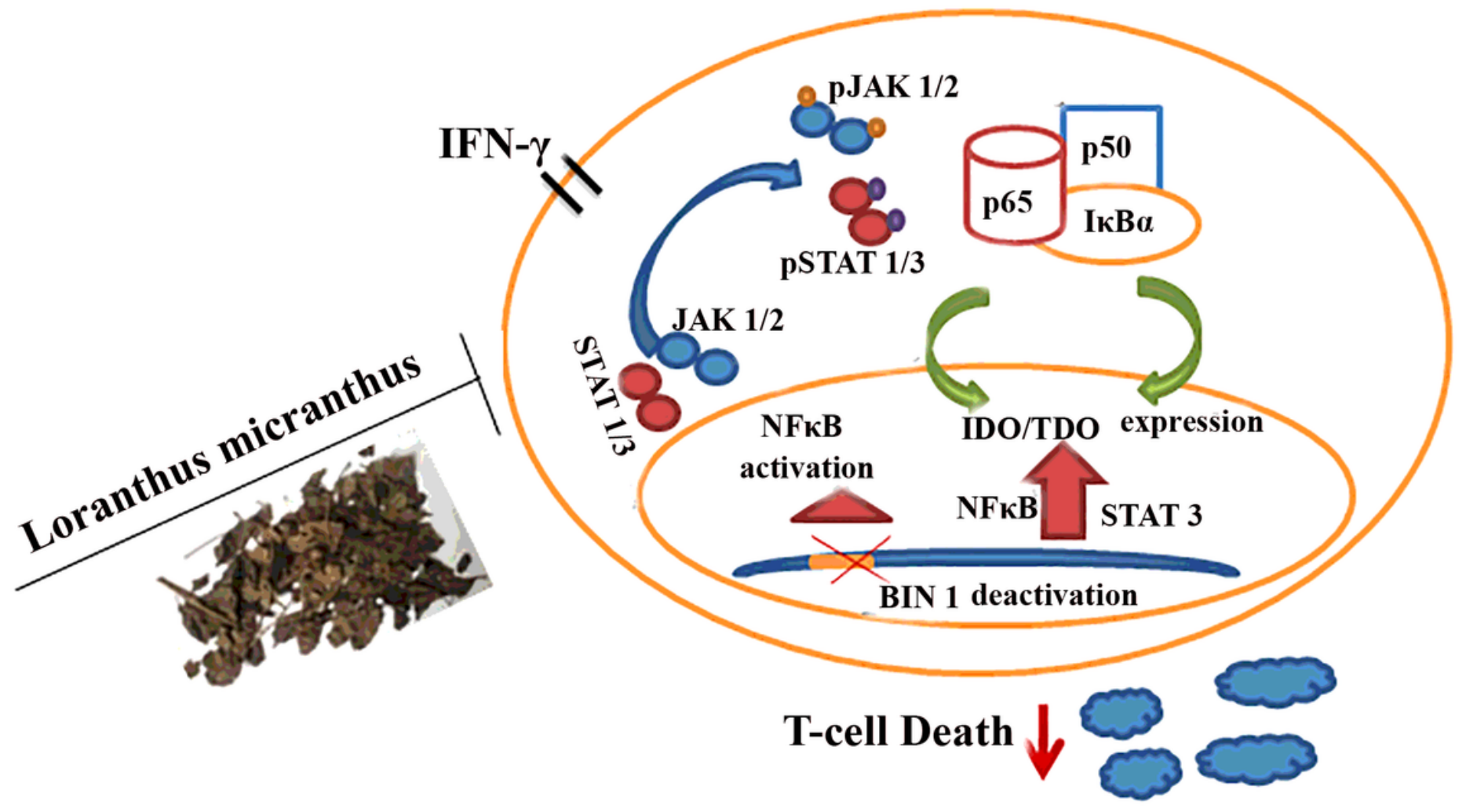

Figure 7 
Mechanism of regulation of IDO 1 by L. micranthus treatment in human breast cancer cells. INF- $Y$ stimulation of breast cancer cells resulted in activation of JAK/STAT pathway via phosphorylation and NFKB pathway by degradation of IKB-a, ultimately leading to inactivation of BIN 1 and decrease in T-cell viability. On the other hand, treatment with L. micranthus extract reversed the entire episode of the INF- $Y$ alterations in breast cancer cells relative to control. 